\title{
Optimal Design of Robust Fractional Order PID for the Flight Control System
}

\author{
Parvesh Kumar \\ Dept. of Electrical Engineering \\ PEC University of Technology \\ Chandigarh, India
}

\author{
Shiv Narayan, PhD \\ Dept. of Electrical Engineering \\ PEC University of Technology \\ Chandigarh, India
}

\author{
Jetesh Raheja \\ Dept. of Electronics \\ Engineering, GJUS\&T \\ Hisar, India
}

\begin{abstract}
Nature inspired algorithms are the most popular and robust algorithms for the optimization of the real world problems like pitch control of an aircraft system. This paper introduces Bat algorithm and Differential Evolution technique for the multi-objective optimization based designing of the fractional order PID (FOPID) and integer order PID controllers. The optimized values obtained from the techniques have been implemented for the Pitch control of an aircraft system to obtain the desired robust response. In this paper a mixed sensitivity $\mathrm{H}_{\infty}$ problem is designed and simulated using Matlab. It has been shown that the design of FOPID using multi-objective bat algorithm gives better results than others.
\end{abstract}

\section{Keywords}

Fractional order PID controller; Bat algorithm; PID optimization; Mixed sensitivity problem; Pitch control of an aircraft system.

\section{INTRODUCTION}

In last few decades, the FOPID has many areas of applications in engineering and science [1-5]. The concept of fractional order was firstly introduced by Pdlubny in 1997 [6]. Y. luo et. al explains that the FOPID gives better performances as compared to the classical methods of tuning PID controllers [7]. The order of the derivative and the integral part of the fractional order PID controllers are in the form of fractions. Control techniques like fuzzy control, neural network, model predictive control and model reference adaptive control have been developed outstandingly. But PID controllers are the most widely used controllers in industries now a days in applications like motor speed control, drive control, temperature control process, level control etc.

This paper interprets a concept of increasing the performances of the PID controller by using FOPID, because of the order of the derivative and the integral part of FOPID are in fraction. A fractional order PID controller have five parameters, i.e., proportional gain, integral gain, derivative gain, integral and derivative order that need to be found that optimizes the performance requirements. A fractional order PID is designed for the closed loop control of the ARX based model for the pitch control from VTOL UAV simulation model is done [8]. Tuning of the multi-objective optimization with GA with weighted sum for three different plant models and comparison of the that technique is done with the Ant Colony method of optimization and Zeigler Nicholas the classical method of tuning PID controller parameter is done [9]. In [10] a PID controller has been designed for the liquid level control system using bat algorithm is done.

In this paper a design of the robust PID and robust $\mathrm{PI}^{\lambda} \mathrm{D}^{\mu}$ is done for the pitch control of the aircraft system using multiobjective bat algorithm and multi-objective differential evolution. The time domain performances and stability criteria are compared for the different methods and it is shown that the bat algorithm give better time domain performances and differential evolution gives better robustness from the external disturbances and noises in case of FOPID designing. Figure 1 shows the longitudinal dynamics of an aircraft, where $\delta_{\mathrm{E}}=$ deflection of the elevator, $\theta=$ pitch angle and $\alpha=$ angle of attack [11].

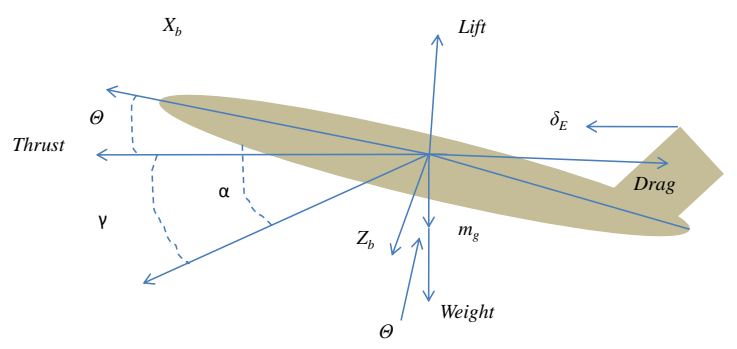

Fig 1: Longitudinal dynamics description of an aircraft

\section{MATHEMATICAL MODELING OF A FLIGHT CONTROL SYSTEM}

Generally the pitch angle of an aircraft system is defined by the geographical earth coordinate, which is fixed for a particular location in terms of longitude and latitude, and the longitudinal dynamics description is given in Figure 1 [11].

The equation that describes the mathematical relations between the deflection of the elevator $\left(\delta_{\mathrm{E}}\right)$ and pitch angle $(\theta)$ is represented below.

$\dddot{\theta}(t)+\left(\frac{1}{\tau_{1}}+\frac{1}{\tau_{2}}\right) \ddot{\theta}(t)+\left(\frac{1}{\tau_{1} \tau_{2}}\right) \dot{\theta}(t)=\frac{k}{\tau_{1} \tau_{2}}\left(\tau_{3} \dot{\delta}_{E}(t)+\delta_{E}(t)\right)$

The equation 1 shown above can be represented as a transfer function, where pitch angle $(\theta)$ is the output and the deflection of the elevator $\left(\delta_{\mathrm{E}}\right)$ is the input.

$\frac{\theta(s)}{\delta_{E}(s)}=\frac{K\left(s \tau_{3}+1\right)}{s\left(\left(s \tau_{1}+1\right)\left(s \tau_{2}+1\right)\right)}$

where the values of $\tau_{1}, \tau_{2}, \tau_{3}$ and $\mathrm{k}$ are $0.8995+0.0968 \mathrm{i}$, 0.8995-0.0968i, 1.0824 and -1.1346 respectively, for a Delta aircraft (flight condition 3) [12]. The transfer function obtained from these values is given below.

$\frac{\theta(s)}{\delta_{E}(s)}=\frac{-1.228 s-1.135}{0.8185 s^{3}+1.799 s^{2}+s}$ 


\section{FRACTIONAL ORDER PID $\left(\right.$ PI $\left.^{\lambda} D^{\mu}\right)$ CONTROLLER}

The standard representation of the PID controller's transfer function is given below.

$C(s)=K_{p}+\frac{K_{i}}{s}+K_{d} s$

Where $K_{p}, K_{i}$ and $K_{d}$ are the gain parameters for the proportional, integral and differential term of the PID controller. $\mathrm{C}(\mathrm{s})$ is the controller transfer function.

The transfer function of the FOPID is given below:

$$
C(s)=K_{p}+K_{i} s^{-\lambda}+K_{d} s^{\mu}
$$

The fractional order PID controller has five parameter that needs to be designed in which three parameters are same as the classical PID controller and two fractional parameters are $\lambda$ and $\mu$. The benefit of using the FOPID is that it gives more flexibility to the objective function that is to be optimized.

\section{OBJECTIVE FUNCTION}

The objective functions are taken in the form of the mixed sensitivity control where the $\mathrm{H}_{\infty}$ norm of the weighted sensitivity and the complimentary sensitivity functions are optimized to get the robustness form the external disturbance and measurement noised [13]. In this paper the optimized values of the fractional order controller parameters are obtained using bat algorithm and differential equation weighted multi-objective problem given below.

$f=w \mid \mathrm{S}(\mathrm{s})\left\|_{\infty}+(1-w)\right\| T(s) \|_{\infty}$

where $\mathrm{w}$ is the weight.

$\|\mathrm{S}(\mathrm{jw})\|_{\infty}$ is the sensitivity function

$\|\mathrm{T}(\mathrm{jw})\|_{\infty}$ is the complementary sensitivity function.

$\mathrm{S}(\mathrm{s})$ is the transfer function between the output and the disturbance and $\mathrm{T}(\mathrm{s})$ is the transfer function between the output and the input.

If ' $\mathrm{P}$ ' denotes the transfer function of the aircraft pitch control system and ' $\mathrm{K}$ ' denotes the controller then sensitivity function and complementary function are given by:

$$
\begin{aligned}
& S(s)=(1+P K)^{-1} \\
& T(s)=P K(1+P K)^{-1}
\end{aligned}
$$

\section{FOPID TUNING USING BAT ALGORITHM AND DE}

Tuning of the FOPID controller is done using bat algorithm and differential equation to find the optimal values of the fractional order PID controller parameters $\left[\mathrm{K}_{\mathrm{p}}, \mathrm{K}_{\mathrm{i}}, \mathrm{K}_{\mathrm{d}}, \lambda, \mu\right]$ the weighted objective function given in equation 6 is minimized. The lower bounds and the upper bounds for the

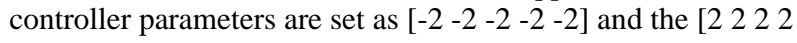
2] respectively. The particular range of the bounds are designed so that the optimization take less time to find the optimal values of the FOPID controller parameters and the range of the bounds is selected by performing the number of experiments. From these experiments it is found that the optimum solution is in between the upper bound and the lower bound. If the range of the optimization is increased then the problem may not lead to a solution which is optimum.
Table 1. Bat Algorithm parameters for optimization

\begin{tabular}{|c|c|}
\hline Bat Algorithm Parameters & Values \\
\hline Population size & 20 \\
\hline No. of Generations & 1000 \\
\hline Loudness & 0.25 \\
\hline Pulse Rate & 0.5 \\
\hline Minimum frequency & 0 \\
\hline Maximum Frequency & 2 \\
\hline
\end{tabular}

Table 2. DE parameters for optimization

\begin{tabular}{|c|c|}
\hline DE Parameters & Values \\
\hline Population size & 20 \\
\hline No. of Generations & 1000 \\
\hline Value of reach & 0.4 \\
\hline Crossover probability & 1 \\
\hline DE-Step size weight & 0.85 \\
\hline
\end{tabular}

The optimized values of the controller parameters using bat algorithm are [ $\left.\begin{array}{lllll}-1.7518 & -0.8070 & -1.8146 & 0.0217 & 1.0457\end{array}\right]$ and using differential evolution are $[-0.6419,-8.4194 \mathrm{e}-05$, $0.1786,1.0658,0.5004]$ the controller's transfer functions for both bat algorithm and differential evolution are shown below.

$$
\begin{aligned}
& C_{1}(s)=-1.7518-0.8070 s^{-0.0217}-1.8146 s^{1.0457} \\
& C_{2}(s)=-0.6419-8.4194 e^{-5} s^{-1.0658}+0.1786 s^{0.5004}
\end{aligned}
$$

The optimized value of the objective function is 0.50035 and 0.3950 using bat algorithm and Differential evolution, as the value of the objective functions are less than 1 . So the system is robust in nature.

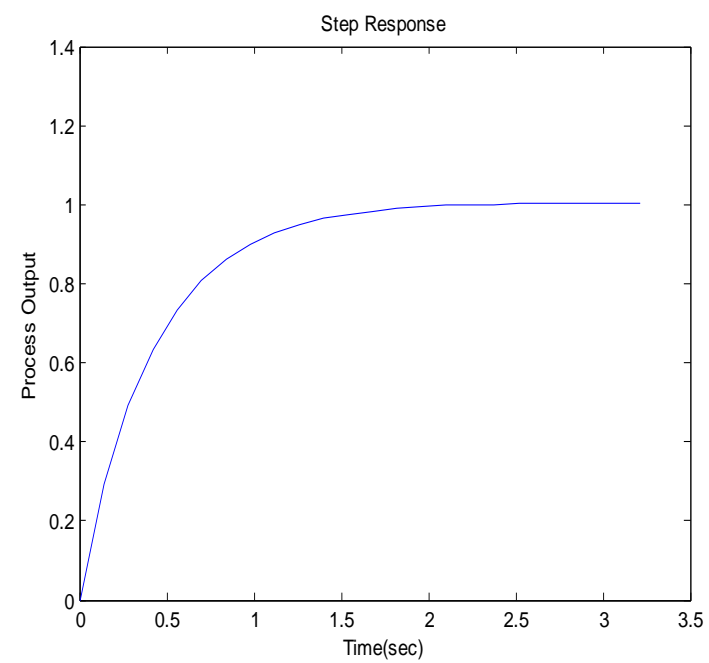

Fig 2: Best closed loop step response with FOPID controller using Bat Algorithm. 


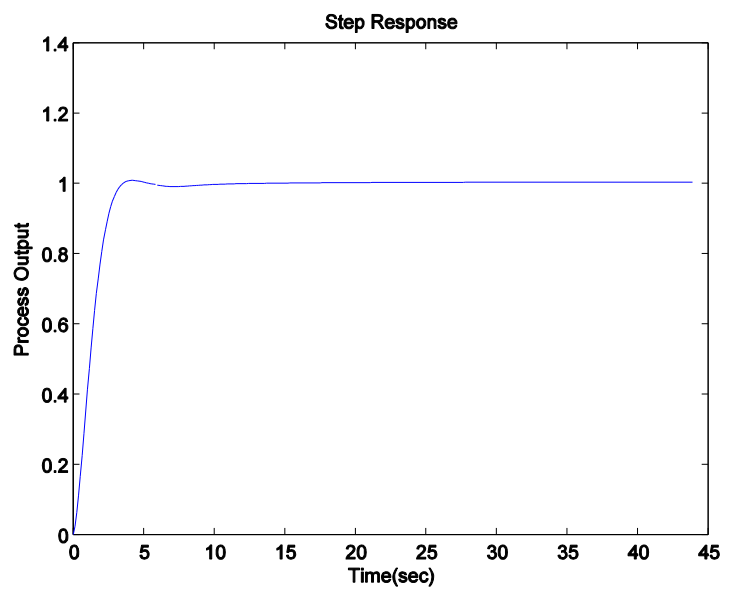

Fig 3: Best closed loop step response with FOPID controller using DE.

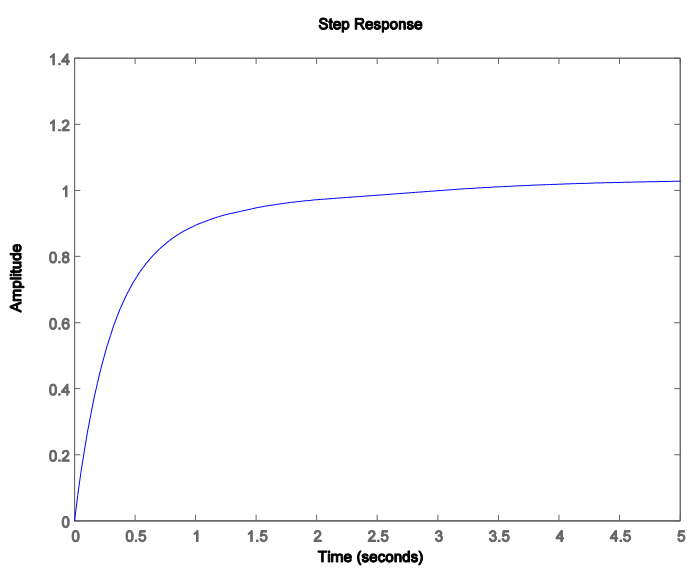

Fig 4: Best closed loop step response with PID controller using Bat Algorithm.

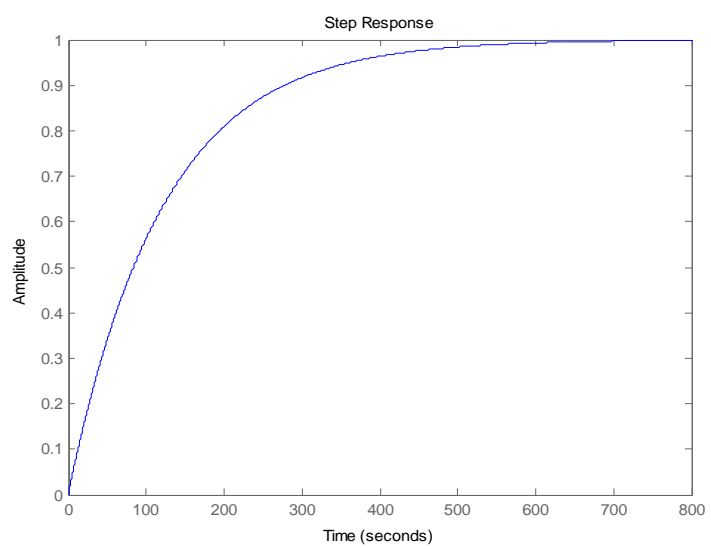

Fig 5: Best closed loop step response with PID controller using DE.

\section{SIMULATION RESULTS}

This paper unravels the optimization of the FOPID and PID controller parameters using bat algorithm and differential evolution by considering the robust stability criteria. Figure 7 shows comparison of the best closed loop step response with FOPID and PID controllers using bat algorithm and differential evolution for the pitch control of the aircraft system, from the graphs it is clear that the multi-objective bat algorithm gives better performances than the multi-objective differential evolution. Table $\mathrm{V}$ and Table VI shows the comparison of the results obtained after the different optimization techniques using FOPID and PID controllers respectively. From the results obtained it is clear that the decreased in the rise time, settling time and overshoot percentage in case of the bat algorithm.

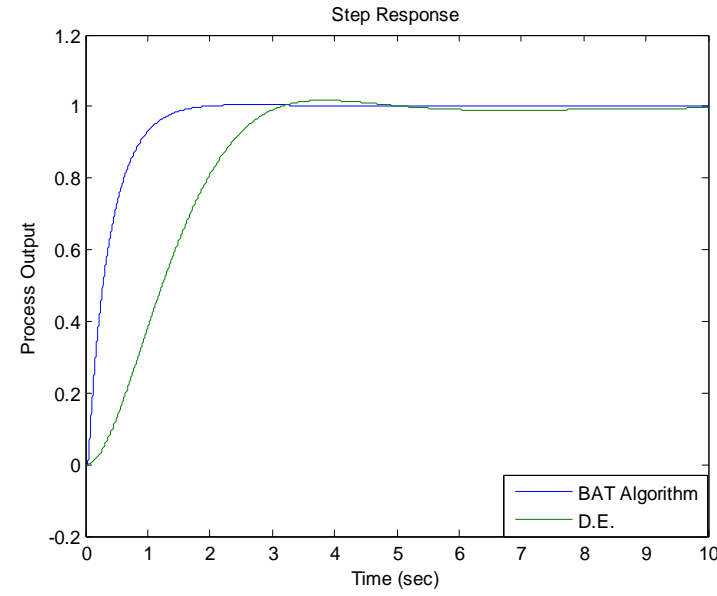

Fig 6: Compared closed loop step response of the system with MODE and MOBA optimized FOPID controllers.

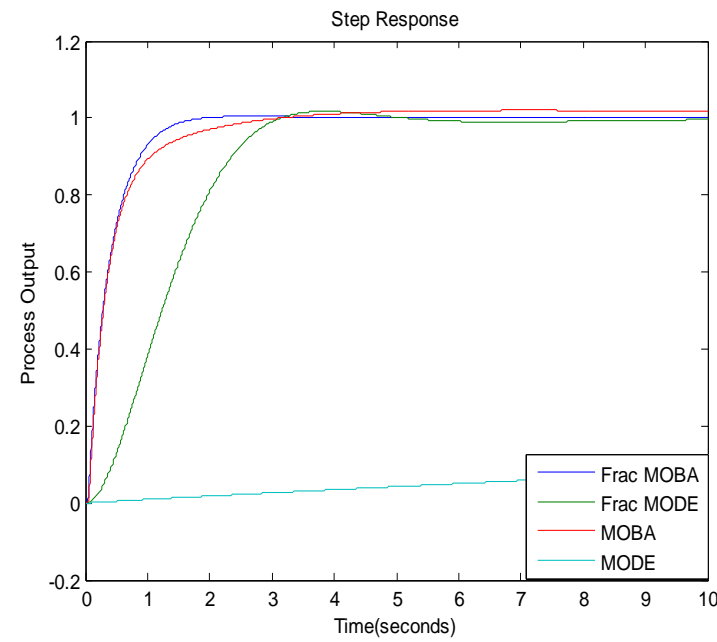

Fig 7: Compared closed loop step response of the system with MODE and MOBA optimized FOPID and PID controllers.

Table 3. Comparison values of FOPID

\begin{tabular}{|c|c|c|}
\hline \multirow{2}{*}{$\begin{array}{c}\text { Optimized } \\
\text { Parameters }\end{array}$} & \multicolumn{2}{|c|}{$\begin{array}{c}\text { Values of the objective function with } \\
\text { FOPID }\end{array}$} \\
\cline { 2 - 3 } & $\boldsymbol{B A}$ & $\boldsymbol{D E}$ \\
\hline $\mathbf{K}_{\mathbf{p}}$ & -1.7518 & -0.6419 \\
\hline $\mathbf{K}_{\mathbf{i}}$ & -0.8070 & $-8.4194 \mathrm{e}^{-05}$ \\
\hline $\mathbf{K}_{\mathbf{d}}$ & -1.8146 & -0.1786 \\
\hline$\lambda$ & 0.0217 & 1.0658 \\
\hline$\mu$ & 1.0457 & 0.5004 \\
\hline
\end{tabular}




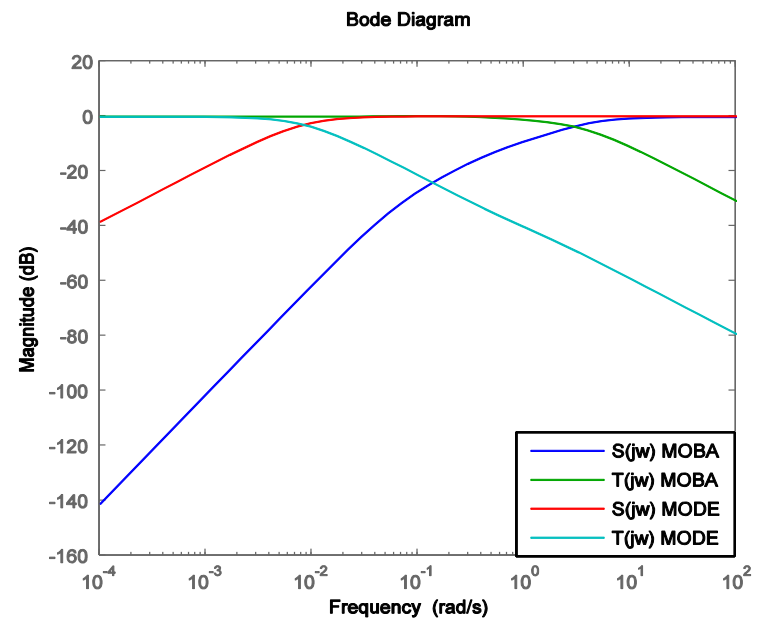

Fig 8: Frequency domain analysis of Sensitivity and Complementary sensitivity function with MOBA and MODE tuned PID controllers.

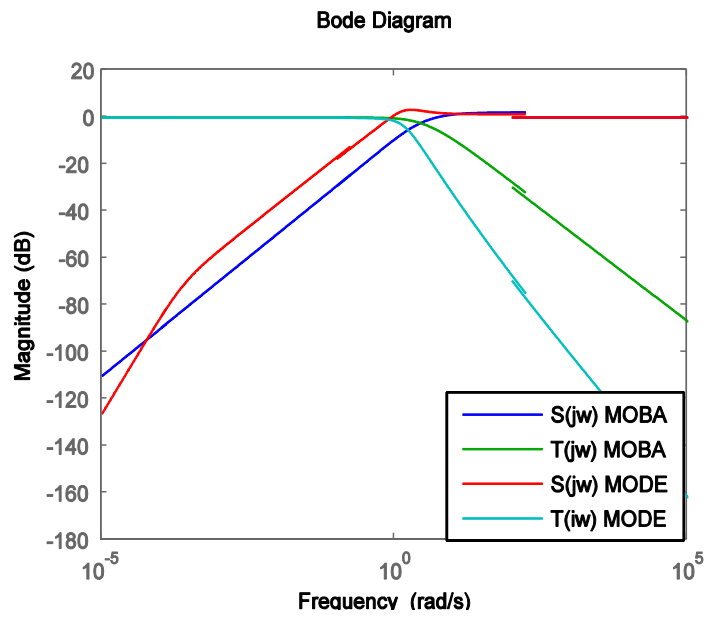

Fig 9: Frequency domain analysis of Sensitivity and Complementary sensitivity function with MOBA and MODE tuned FOPID controllers.

Table 4. Comparison values of PID

\begin{tabular}{|c|c|c|}
\hline \multirow{2}{*}{$\begin{array}{c}\text { Optimized } \\
\text { Parameters }\end{array}$} & \multicolumn{2}{|c|}{ Values of the objective function with PID } \\
\cline { 2 - 3 } & $\boldsymbol{B A}$ & $\boldsymbol{D E}$ \\
\hline $\mathbf{K}_{\mathbf{p}}$ & -1.8343 & -0.0073 \\
\hline $\mathbf{K}_{\mathbf{i}}$ & -0.0992 & $-2.9207 \mathrm{e}^{-23}$ \\
\hline $\mathbf{K}_{\mathbf{d}}$ & -1.9673 & -0.0072 \\
\hline
\end{tabular}

Table 5. Comparison of Results using FOPID

\begin{tabular}{|c|c|c|}
\hline Performances & Bat Algorithm & DE \\
\hline Rise time & 0.95 & 2.25 \\
\hline Settling time & 1.27 & 3.2 \\
\hline Overshoot & $0.00 \%$ & $0.78 \%$ \\
\hline$\|S(j w)\|_{\infty}$ & 0.2378 & $1.797 \mathrm{e}^{-4}$ \\
\hline$\|T(j w)\|_{\infty}$ & 0.7629 & 0.3948 \\
\hline
\end{tabular}

Table 6. Comparison of Results using PID

\begin{tabular}{|c|c|c|}
\hline Performances & Bat Algorithm & DE \\
\hline Rise time & 1.0887 & 484.0080 \\
\hline Settling time & 3.0090 & 587.1682 \\
\hline Overshoot & 0.1770 & 0 \\
\hline$\|S(j w)\|_{\infty}$ & 1 & 1 \\
\hline$\|T(j w)\|_{\infty}$ & 1.0149 & 1 \\
\hline
\end{tabular}

\section{CONCLUSIONS}

This paper unravels the capability of the bat algorithm and differential evolution for tuning the controller parameters using the robust stability criteria. In flight control system uncertainties and noises are inherently present, so the control system must be robust from such kind of uncertainties. The bat algorithm gives the better results in terms of the time domain performances but differential evolution gives the better robustness to the control system from the external disturbances and noise in case of fractional order PID, bat algorithm gives better time domain performances designing the conventional PID than the differential equation.

\section{REFERENCES}

[1] Miller, Kenneth S., and Bertram Ross. "An introduction to the fractional calculus and fractional differential equations." (1993).

[2] Oustaloup, A. "Fractional order sinusoidal oscillators: optimization and their use in highly linear FM modulation." Circuits and Systems, IEEE Transactions on28.10 (1981): 1007-1009

[3] Chengbin, Ma, and Y. Hori. "The application of fractional order PID controller for robust two-inertia speed control." Proceedings of the 4th International Power Electronics and Motion Control Conference, Xi'an, August. 2004.

[4] Kadiyala, Venu Kishore, Ravi Kumar Jatoth, and Sake Pothalaia. "Design and implementation of Fractional Order PID controller for aerofin control system."Nature \& Biologically Inspired Computing, 2009. NaBIC 2009. World Congress on. IEEE, 2009.

[5] Ahuja, Ashu, Shiv Narayan, and Jagdish Kumar. "Robust FOPID controller for load frequency control using Particle Swarm Optimization." Power India International Conference (PIICON), 2014 6th IEEE. IEEE, 2014

[6] Podlubny, I., L. Dorcak, and I. Kostial. "On fractional derivatives, fractional-order dynamic system and PIDcontrollers." Proceedings of the 36th conference on decision \& control. Vol. 5. 1997.

[7] Luo, Ying, et al. "Tuning fractional order proportional integral controllers for fractional order systems." Journal of Process Control 20.7 (2010): 823-831.

[8] Han, Jinlu, et al. "Pitch Loop Control of a VTOL UAV Using Fractional Order Controller." Journal of Intelligent \& Robotic Systems 73.1-4 (2014): 187-195.

[9] Kumar, Parvesh, Jitesh Raheja, and Shiv Narayan. "Design Of Pid Controllers Using Multiobjective 
International Journal of Computer Applications (0975 - 8887)

Volume 128 - No.14, October 2015

Optimization with GA And Weighted Sum Objective Function Method." Small 2.2 (2013).

[10] Katal, Nitish, Parvesh Kumar, and Shiv Narayan. "Optimal PID controller for coupled-tank liquid-level control system using bat algorithm." Power, Control and Embedded Systems (ICPCES), 2014 International Conference on. IEEE, 2014.

[11] Mohanty, C. S., P. S. Khuntia, and D. Mitra. "Design of a $\mathrm{T}$ factor based RBFNC for a flight control system." Advances in Artificial Intelligence 2014 (2014): 2.

[12] Donald. 1936 McLean. Automatic flight control systems. Prentice-Hall Incorporated, 1990.

[13] U. Chaiya and S. Kaitwanidvilai, "Fixed structure robust DC motor speed control," Proceeding of the International Multiconference of Engineering and Computer Scientists, vol. II, March 2009, pp. 18-20. 